\title{
Biofilm-specific uptake of a 4-pyridone-based iron chelator by Pseudomonas aeruginosa
}

\author{
Sharareh Houshmandyar • Ian M. Eggleston (10) Albert Bolhuis 10
}

Received: 9 June 2020/ Accepted: 21 December 2020/Published online: 11 January 2021

(C) The Author(s) 2021

\begin{abstract}
Iron is an essential nutrient for virtually all microbes and limiting the concentration of available iron is a potential strategy to be used as an alternative to antibiotic treatment. In this study we analysed the antimicrobial activity of two chelators, specifically 3-hydroxy-1,2-dimethyl-4(1H)-pyridone (deferiprone, DFP), which is clinically approved for the treatment of iron overload disorders, and its 1,2-diethyl homologue, CP94. Both compounds showed moderate activity towards planktonically growing $P$. aeruginosa cells, and the mechanism of action of these chelators was indeed by limiting the amount of free iron. Surprisingly, the compounds behaved very differently when the cells were grown in biofilms. DFP also showed inhibitory effects on biofilm formation but in contrast, CP94 stimulated this process, in particular at high concentrations. We hypothesised that CP94 behaves as an iron carrier, which was confirmed by our observation that it had antimicrobial synergy with the toxic metals, gallium and copper. This suggests that $P$. aeruginosa produces a biofilm-specific transport protein that recognises CP94 but not the closely related compound DFP.
\end{abstract}

Supplementary Information The online version contains supplementary material available at https://doi.org/10.1007/ s10534-020-00281-x.

S. Houshmandyar · I. M. Eggleston · A. Bolhuis ( $\square)$ Department of Pharmacy and Pharmacology, University of Bath, Bath BA2 7AY, UK

e-mail: a.bolhuis@bath.ac.uk
Keywords CP94 · Deferiprone (DFP) · Iron chelator $\cdot$ Pseudomonas aeruginosa $\cdot$ Biofilm

\section{Introduction}

Iron is essential for virtually all living organisms as it is required in many fundamental cellular processes such as respiration and nucleic acid metabolism (Daher et al. 2017). In the human body, most iron is not freely available as it is bound to hemoproteins and other iron-binding proteins such as transferrin, ferritin and lactoferrin. As a result, the concentration of free iron is very low, which has several important consequences. Firstly, iron can be toxic as, due to its redox potential, it has the capacity to lose and gain electrons in a biological environment leading to the generation of reactive oxygen species (ROS). Limiting the labile iron pool thus reduces the potential for iron-mediated oxidative damage to tissues (Cabantchik 2014). Secondly, low levels of labile iron ensure that this nutrient is not readily available to pathogenic microorganisms, which require iron for many processes including virulence, infectivity and biofilm formation (Begg 2019). To overcome this, bacteria have developed several mechanisms to acquire iron from the host, by for instance the secretion of siderophores, which are low molecular weight compounds with high affinity for ferric iron and which sequester and 
transport ferric iron into bacterial cells (Hider and Kong 2010; Neilands 1995).

As iron is such an important nutrient for pathogens, a number of studies have attempted to use iron chelators as antimicrobial agents, either as an alternative or addition to antibiotic treatment. Indeed, several chelators have been shown to have antimicrobial activity either alone or in combination with antibiotics or antifungals. This includes two clinically-approved chelators that are used for the treatment of ironoverload diseases, namely deferoxamine (DFO) (Lowy et al. 1984; Moon et al. 2011; van Asbeck et al. 1983a) and deferiprone (DFP) (Lai et al. 2016; Thompson et al. 2012; Zarember et al. 2009). However, the literature on the activity on these chelators appears contradictory. For instance, one study showed there was no activity for DFO against a range of common bacterial pathogens (Thompson et al. 2012), whereas another study (Kim and Shin 2009) showed that its activity on staphylococci is strain- and speciesdependent and sometimes even stimulatory towards bacterial growth. Furthermore, it has been shown that while DFP can be inhibitory to growth of Pseudomonas aeruginosa, at sub-inhibitory concentrations it can stimulate growth by acting as an iron carrier (Visca et al. 2013). It was therefore concluded that the therapeutic use of iron chelators should be carefully assessed to avoid the stimulation of growth of particular pathogens.

In this study we analysed the activity of the chelator CP94, which is a 1,2-diethyl analogue of DFP (Fig. 1). It has been shown to be more effective than DFP in removing iron in a number of mammalian model species such as rat (Singh et al. 1992), but its antimicrobial activity has not been investigated. In this study we compared the activity of both CP94 and

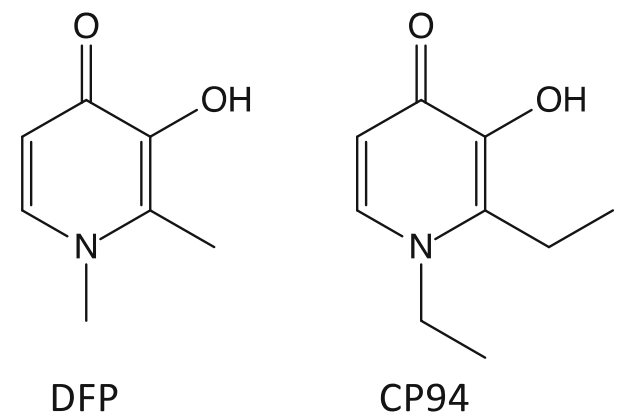

Fig. 1 Chemical structures of the hydroxypyridone iron chelators used in this study, DFP and CP94
DFP on $P$. aeruginosa, which is a common opportunistic pathogen that can cause, for instance, lung and wound infections (Mulcahy et al. 2014). The results show that both chelators have moderate antimicrobial activity against planktonic cells. Surprisingly, the chelators were shown to behave very differently when the bacteria were grown as biofilms: DFP was inhibitory at high concentrations, but CP94 stimulated biofilm formation as it was taken up selectively by $P$. aeruginosa cells in the biofilm state.

\section{Experimental}

Bacterial strains and growth conditions

The following $P$. aeruginosa strains were used in this study: $P$. aeruginosa PAO1 (Holloway 1955), $P$. aeruginosa $\Delta p v d A \Delta p c h D$ PAO1 ( $\Delta \Delta \mathrm{PAO} 1)$ (Visca et al. 2013) and $P$. aeruginosa IST27 (Leitão et al. 1996). PAO1 is a commonly used laboratory strain, whereas IST27 is a mucoid strain isolated from a cystic fibrosis patient. Other species that were used are Escherichia coli BW25113 (Grenier et al. 2014) and Salmonella enterica serovar Typhimurium NTB6 (Kortman et al. 2015). Bacteria were grown as indicated in lysogeny broth (LB; $10 \mathrm{~g} / \mathrm{L}$ tryptone, $5 \mathrm{~g} / \mathrm{L}$ yeast extract, $10 \mathrm{~g} / \mathrm{L} \mathrm{NaCl}$ ) or Iscove's Modified Dulbecco's Medium (IMDM; Sigma-Aldrich). For planktonic growth experiments, pre-cultures were grown overnight in a shaking incubator at $37{ }^{\circ} \mathrm{C}$, diluted 100-fold in fresh medium and growth was continued at $37{ }^{\circ} \mathrm{C}$. For biofilm experiments, IMDM was supplemented with $0.5 \%$ glucose, and the biofilms were grown as indicated below.

\section{Minimum inhibitory concentrations}

Minimum inhibitory concentrations (MIC) values of DFP (Sigma-Aldrich) or CP94 (Chemspace) were determined using a macrobroth dilution method as described (Andrews 2001), using either LB or IMDM as the growth medium. Concentrated stock solutions were made in DMSO (CP94) or water (DFP); final concentrations of solvent were $<1 \%$, which did not impact the outcome of the experiments. Experiments with IMDM were done in the presence of $10 \mu \mathrm{M}$ ferric ammonium citrate where indicated. 
Biofilm assays

Biofilms were grown as previously described (Beeton et al. 2014) with minor modifications. Briefly, overnight bacterial cultures were grown in IMDM and diluted to an optical density at $600 \mathrm{~nm}$ (OD600) of 0.05 in fresh IMDM supplemented with $0.5 \%$ glucose. These inoculums were dispensed $(200 \mu \mathrm{L})$ into 96-well plate wells (Costar, Corning). Afterwards, the plates were incubated for $24 \mathrm{~h}$ at $37^{\circ} \mathrm{C}$ on an orbital rotating platform (Stuart mini gyro-rocker SSM3) at $20 \mathrm{rpm}$. Following biofilm formation, the supernatant was removed, and wells were washed three times with phosphate buffered saline (PBS; Sigma-Aldrich) followed by drying at $60{ }^{\circ} \mathrm{C}$ for $45 \mathrm{~min}$. The biofilms were then stained with $0.1 \%$ w/v crystal violet for $15 \mathrm{~min}$ and washed three times gently by plunging in lukewarm tap water. Finally, $200 \mu \mathrm{L} \mathrm{30 \%} \mathrm{v/v} \mathrm{acetic} \mathrm{acid} \mathrm{was} \mathrm{added} \mathrm{to} \mathrm{dissolve} \mathrm{the}$ crystal violet and the absorbance at $595 \mathrm{~nm}$ was measured using an automatic plate reader (BMG Labtech). Experiments were performed in the presence or absence of DFP and CP94 and, where indicated, $\mathrm{Ga}_{3}\left(\mathrm{SO}_{4}\right)_{3}$ or $\mathrm{CuCl}_{2}$ (both from SigmaAldrich) were added. All biofilm assays were repeated at least three times independently, with 6 wells per experiment. Absorbance values were normalised to the mean of the control sample, thus expressing biofilm formation as a percentage.

\section{Adherence}

The procedure to measure adherence of cells was similar to biofilm formation, but instead of 96-well plates, 6-well polystyrene plates were used which were inoculated with $2 \mathrm{~mL}$ IMDM containing a 1000-fold diluted overnight culture of $P$. aeruginosa PAO1, similar to previously published methods (Toledo-Arana et al. 2001). Briefly, the plates were incubated for $6 \mathrm{~h}$, after which the plates were washed with PBS twice to remove planktonic cells, followed by drying at $60{ }^{\circ} \mathrm{C}$ and staining with $0.1 \%$ crystal violet. The plates were then washed with lukewarm tapwater as above, after which the plates were observed with light microscopy. It was verified that cells were distributed fairly evenly, and then the number of adherent cells in four randomly chosen fields of view were counted, and each experiment was repeated four times.
Statistical analysis

Data are expressed as the mean \pm standard deviation. Group means were compared using one-way ANOVA, followed by Tukey's or Dunnett's multiple comparison test. Differences were considered statistically significant at $\mathrm{p}$ values of $<0.05$.

\section{Results}

Antimicrobial activity

The activity of DFP and CP94 against $P$. aeruginosa was determined in iron-replete and iron-poor conditions using LB and IMDM, respectively. LB is a nutrient-rich medium which contains, based on data supplied by the manufacturer of its components, 5-12 $\mu \mathrm{M}$ iron, and similar values have also been reported in the literature (Abdul-Tehrani et al. 1999; Cunrath et al. 2016; Diggle et al. 2007). In contrast, IMDM is a chemically defined tissue-culture medium that lacks iron in its formulation. It should be noted, however, that IMDM still supports the growth of $P$. aeruginosa, albeit at a slower rate as compared to LB or IMDM supplemented with iron (data not shown), and also other bacteria such as Escherichia coli and Salmonella enterica can grow in IMDM (Kortman et al. 2015). Iron is essential for growth of these bacteria, indicating that IMDM does contain the low levels of iron that are sufficient to support the growth of these bacteria.

In LB, the MIC values were $1024(7.4 \mathrm{mM})$ and $2048 \mu \mathrm{g} / \mathrm{mL}(12 \mathrm{mM})$ for DFP and CP94, respectively, for both PAO1, a commonly used laboratory strain, and IST27, a mucoid isolate from a cystic fibrosis patient (Table 1). In iron-poor conditions, the

Table 1 MIC values $(\mu \mathrm{g} / \mathrm{mL})$ of DPF and CP94 in different media

\begin{tabular}{lllll}
\hline Compound & Strain & \multicolumn{2}{l}{ Medium } \\
\cline { 3 - 5 } & & LB & IMDM & IMDM $+\mathrm{Fe}^{3+}$ \\
\hline DFP & PAO1 & 1024 & 128 & 1024 \\
& IST27 & 1024 & 128 & 1024 \\
CP94 & PAO1 & 2048 & 256 & 2048 \\
& IST27 & 2048 & 512 & 2048 \\
\hline
\end{tabular}


strains were considerably more sensitive to both chelators, with MIC values being 4-eightfold lower as compared to those in LB. To test whether these lower MIC values in IMDM were due to the absence of iron only, $10 \mu \mathrm{M} \mathrm{Fe}^{3+}$ was added to IMDM, resulting in an iron concentration that is similar to that in LB medium. As shown in Table 1, this indeed resulted in MIC values similar to those observed in LB medium.

The effect of DFP and CP94 on P. aeruginosa biofilm formation.

Next, the effect of DFP and CP94 on biofilm formation of $P$. aeruginosa was tested in IMDM. With DFP, significant reductions in biofilm formation were observed at concentrations above the MIC value, but even at the highest concentration tested $(512 \mu \mathrm{g} / \mathrm{mL}$;
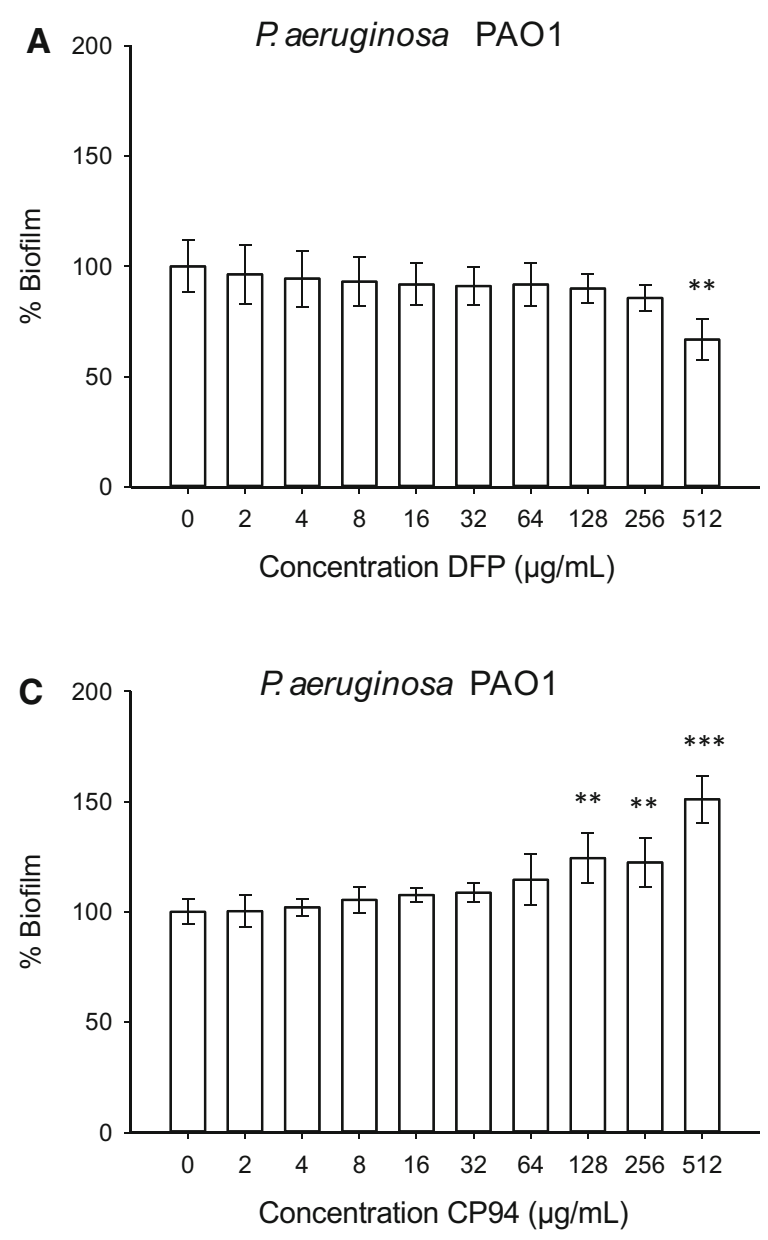

Fig. 2 Effects of the concentration of DFP (panels $\mathbf{a}$ and $\mathbf{b}$ ) and CP94 (panels $\mathbf{c}$ and d) on the biofilm formation in IMDM of PAO1 (panels a and c) and IST27 (panels b and d). The error bars show the standard deviation of 3-4 independent
$3 \mathrm{mM}$ ) still $60-65 \%$ of the biofilm biomass remained (Fig. 2a, b) for both PAO1 and IST27 as compared to the biomass formed in the absence of compound.

At sub-MIC levels of DFP (64 $\mu \mathrm{g} / \mathrm{mL})$, planktonic growth of $P$. aeruginosa PAO1 is reduced (Supplementary Fig. 1), indicating that the reduction in biofilm formation in the presence of DFP is an effect of the reduction in the rate of growth. Planktonic growth was also reduced in the presence of sub-MIC levels of CP94 (Supplementary Fig. 1) but, surprisingly, more biofilm was formed (Fig. 2c, d), which was statistically significant at high concentrations above the MIC. With both PAO1 and IST27, $512 \mu \mathrm{g} /$ $\mathrm{mL} \mathrm{CP94} \mathrm{resulted} \mathrm{in} \mathrm{an} \mathrm{increase} \mathrm{in} \mathrm{biofilm} \mathrm{formation}$ of $50-60 \%$. At this concentration, we also analysed the
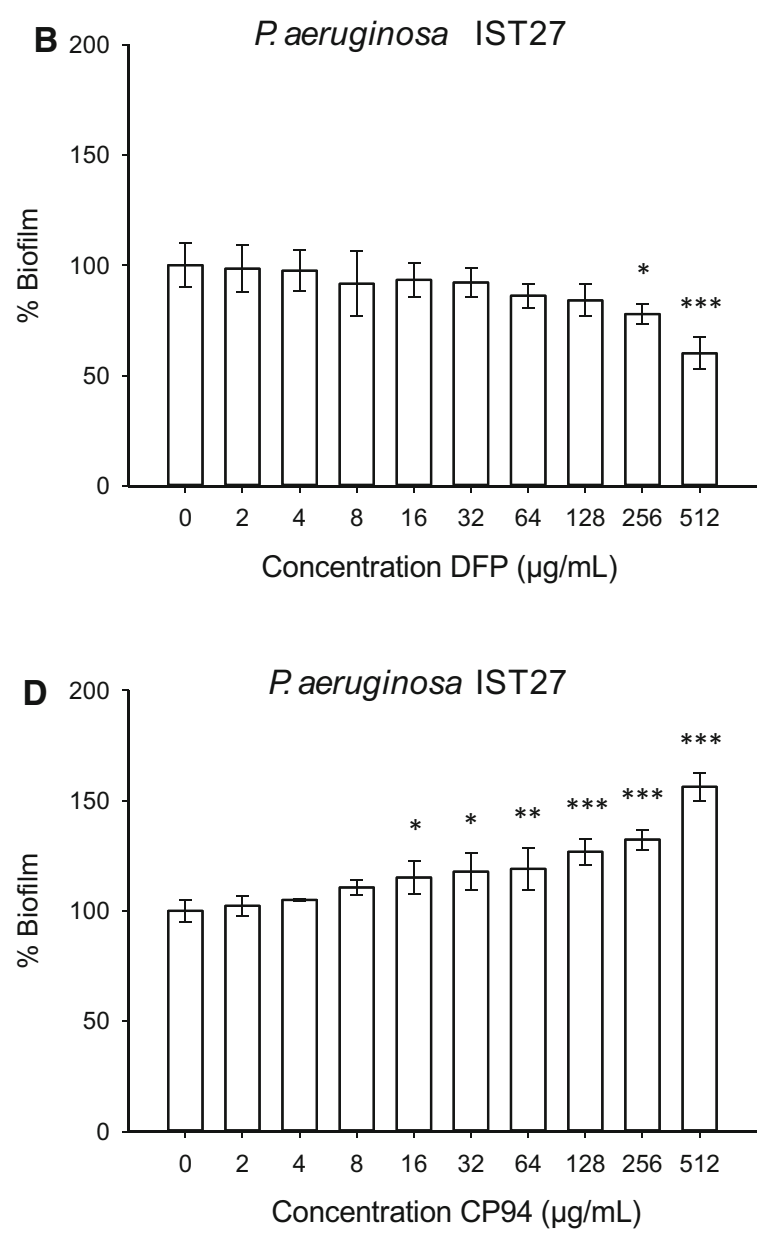

experiments. Significance was compared to the controls $(0 \mu \mathrm{g} /$ $\mathrm{mL}$ ) using a 1-way ANOVA followed by Dunnett's multiple comparison test $(* \mathrm{p}<0.05 ; * * \mathrm{p}<0.01 ; * * * \mathrm{p}<0.001)$ 
effects on the early stages of biofilm formation by counting the number of adherent cells after $6 \mathrm{~h}$ of incubation. In the presence of CP94, we counted $>$ threefold the number of adherent cells as compared to the control: in the presence of CP94 there were $73( \pm 23)$ cells per field of view, whereas there were $22( \pm 7)$ cells per field of view in the absence of CP94; this difference was statistically significant ( $\mathrm{n}=4$; Student's t-test, $\mathrm{p}=0.01$ ).

The effect of CP94 on E. coli BW25113 and S. Typhimurium NTB6.

In view of these results, we decided to investigate whether CP94 could also potentiate the biofilm formation of two other Gram-negative bacteria, i.e. E. coli and S. Typhimurium. Interestingly, CP94 inhibited biofilm formation of both of these bacteria (Fig. 3), suggesting that the stimulatory effect of CP94 is specific to $P$. aeruginosa, in particular considering that the MIC values for CP94 against $E$. coli and $S$. Typhimurium were in the same range as for $P$. aeruginosa, with values of 128 and $512 \mu \mathrm{g} / \mathrm{mL}$, respectively.

The effect CP94 on P. aeruginosa PAO1 $\triangle \mathrm{pvdA}$ $\Delta \mathrm{pchD}$.

As shown above, the effect of DFP and CP94 is very similar towards planktonic cells, but the outcome is very different when $P$. aeruginosa is growing as biofilms in iron-poor conditions. We speculated that CP94 but not DFP might be taken up by cells in biofilms and act as an iron carrier. To investigate this

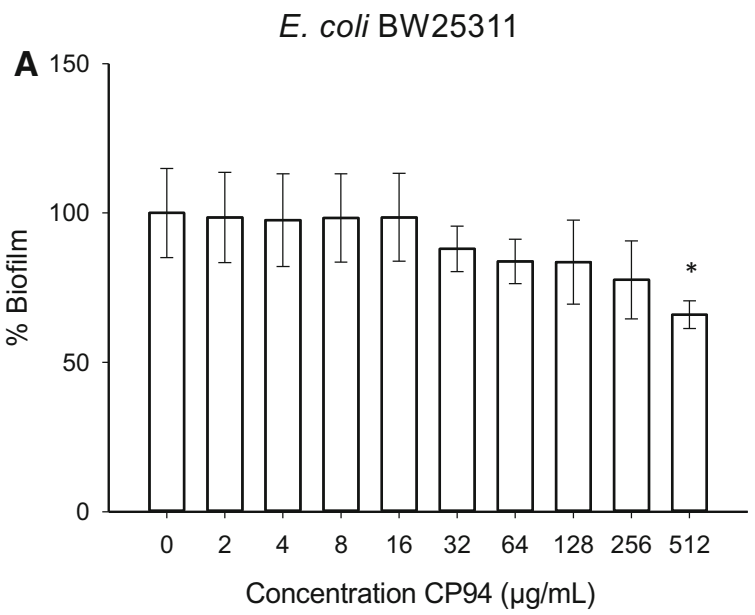

Fig. 3 Effects of the concentration of CP94 (panels a and b) on the biofilm formation of E. coli BW25113 (a) and $S$. Typhimurium NTB6 (b) in IMDM. The error bars show the standard deviation of 3 independent experiments. Significance in more detail, the effects of CP94 were investigated on PAO1 $\Delta p v d A \Delta p c h D(\Delta \Delta \mathrm{PAO} 1)$, a mutant of PAO1 that does not produce its two endogenous iron carriers, the siderophores pyochelin and pyoverdine (Visca et al. 2013). As planktonic cells, this mutant had the same resistance to DFP as the parental strain, and was somewhat less resistant to CP94, albeit that this differed by only one doubling dilution and therefore not significant (CP94 MIC values: LB, $1024 \mu \mathrm{g} / \mathrm{mL}$; IMDM, $256 \mu \mathrm{g} / \mathrm{mL}$; IMDM $+\mathrm{Fe}^{3+}$, $1024 \mu \mathrm{g} / \mathrm{mL}$ ). As planktonic cells, $\Delta \Delta \mathrm{PAO} 1$ grows slower than the parental strain in IMDM, but biofilm formation is at similar levels (data not shown). When testing the effects of CP94 on biofilm formation, the stimulation of biofilm formation was even more pronounced as observed with PAO1 or IST27; in this case, at a concentration of $512 \mu \mathrm{g} / \mathrm{mL}$ the increase in biomass was 3.5-fold (Fig. 4a). The effect of DFP on $\triangle \triangle \mathrm{PAO} 1$ was similar as observed for the parental strain, with a reduction in biofilm formation to approximately $50 \%$ at a concentration of $512 \mu \mathrm{g} / \mathrm{mL}$ (Fig. 4b).

The combined effect of $\mathrm{CP} 94$ with either $\mathrm{Ga}^{3+}$ or $\mathrm{Cu}^{2+}$ on P. aeruginosa biofilm formation.

We hypothesised that if CP94 indeed acts as an iron carrier, it also might promote the uptake of other metals such as $\mathrm{Ga}^{3+}$ or $\mathrm{Cu}^{2+}$ and, since these are toxic to bacteria, CP94 should increase the antimicrobial activity of these metals towards $P$. aeruginosa. To test this, we firstly determined the concentrations of $\mathrm{Ga}^{3+}$

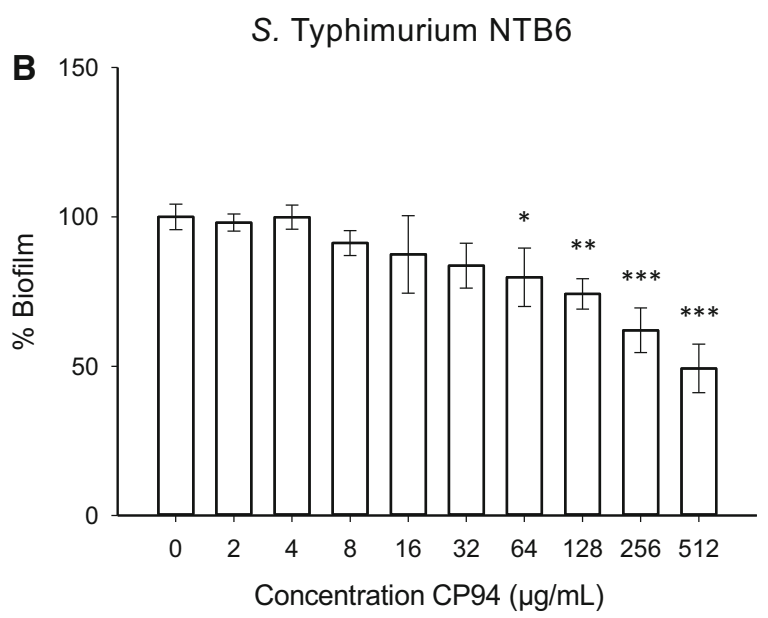

was compared to the controls $(0 \mu \mathrm{g} / \mathrm{mL})$ using a one-way ANOVA followed by Dunnett's multiple comparison test $(* \mathrm{p}<0.05 ; * * \mathrm{p}<0.01 ; * * * \mathrm{p}<0.001)$ 


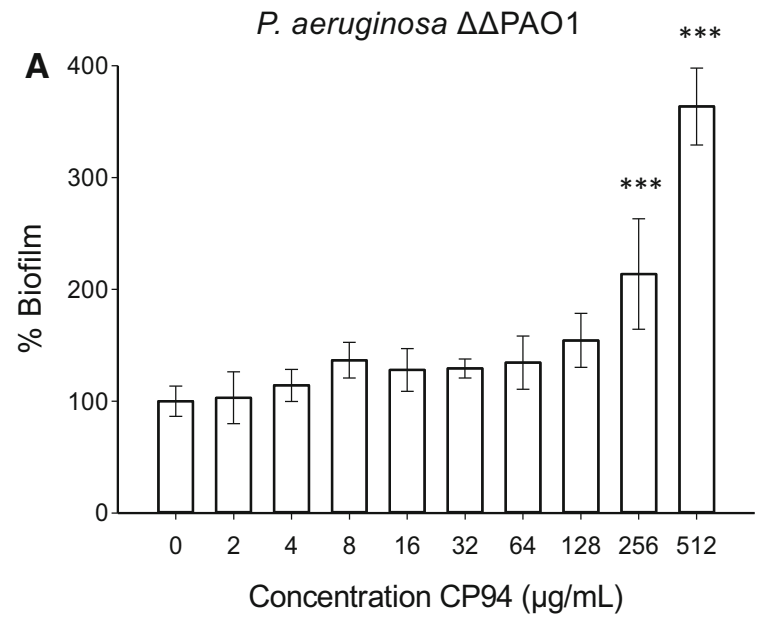

Fig. 4 Effect of CP94 and DFP on the biofilm formation of $\triangle \triangle \mathrm{PAO} 1$ in IMDM. The error bars show the standard deviation of 3 independent experiments. Significance was compared to the

or $\mathrm{Cu}^{2+}$ salts that resulted in a moderate $(20-40 \%)$ inhibition of biofilm formation in IMDM, which was $1 \mu \mathrm{M}$ and $1 \mathrm{mM}$ respectively. These concentrations were then combined with a low concentration of CP94 $(2 \mu \mathrm{g} / \mathrm{mL}=12 \mu \mathrm{M})$ and added to biofilms of the three $P$. aeruginosa strains used (PAO1, IST27, and $\Delta \Delta$ PAO1). As shown in Fig. 5 , in all strains tested the biomass of biofilms treated with a CP94-Ga complex was significantly reduced when compared to treatment with $\mathrm{CP} 94$ or $\mathrm{Ga}^{3+}$ alone. In the case of copper, which by itself is less toxic than gallium, these trends were the same albeit that the differences were not always statistically significant (e.g. IST27 Fig. 5D). Thus, CP94 enhances the antimicrobial activity of both $\mathrm{Ga}^{3+}$ and $\mathrm{Cu}^{2+}$, but to verify that was indeed a biofilm-specific effect, the CP94-Ga complex was also tested on planktonic cells. As shown in Supplementary Fig. 2, this complex or its individual components did indeed not have an effect on the growth rate of $P$. aeruginosa PAO1 and IST27, confirming that the effects seen are biofilm-specific. We also tested whether DFP increased the antimicrobial activity of $\mathrm{Ga}^{3+}$, but there was no difference in the presence of DFP when combined with $1 \mu \mathrm{M} \mathrm{Ga}^{3+}$ (Supplementary Fig. 3).

The combined effect of CP94 with $\mathrm{Fe}^{3+}$ on $\mathrm{P}$. aeruginosa biofilm formation.

Above we demonstrate that $2 \mu \mathrm{g} / \mathrm{mL}(12 \mu \mathrm{M})$ CP94 enhances the antimicrobial activity of toxic metals. Using the same concentration of CP94, we also
$P$. aeruginosa $\triangle \triangle \mathrm{PAO} 1$

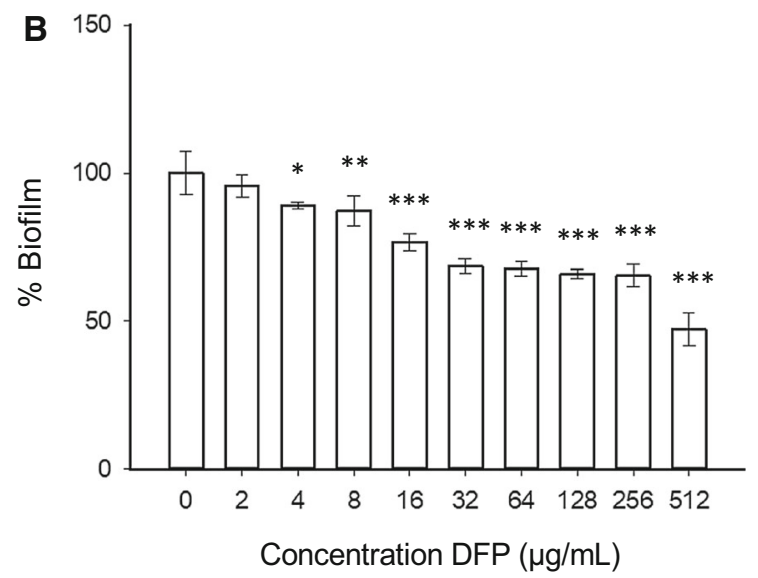

control $(0 \mu \mathrm{g} / \mathrm{mL})$ using a one-way ANOVA followed by Dunnett's multiple comparison test $(* \mathrm{p}<0.05$; **p $<0.01$; $* * * \mathrm{p}<0.001)$

analysed what the effect on biofilm formation of $P$. aeruginosa $\mathrm{PAO} 1$ is in the presence of CP94 saturated with $\mathrm{Fe}^{3+}$, and the same concentration of $\mathrm{Fe}^{3+}$ without CP94. As CP94 forms a 3:1 complex with $\mathrm{Fe}^{3+}$, the concentration of $\mathrm{Fe}^{3+}$ used here was $4 \mu \mathrm{M}$. As shown in Fig. 6, both $\mathrm{Fe}^{3+}$ alone and $\mathrm{CP} 94$ plus $\mathrm{Fe}^{3+}$ stimulated biofilm formation, and this was statistically significant. There was no significant difference between bioiflms grown in the presence of CP94 with $\mathrm{Fe}^{3+}$ or $\mathrm{Fe}^{3+}$ alone, indicating that at a concentration of $4 \mu \mathrm{M} \mathrm{Fe}{ }^{3+}$, the transport of $\mathrm{Fe}^{3+}$ is not a rate limiting factor for biofilm formation. Higher concentrations of CP94, or CP94 saturated with $\mathrm{Fe}^{3+}$, did not further increase the amount of biofilm formed (data not shown).

\section{Discussion}

Iron is an important nutrient for most microbes, and bacteria such as $P$. aeruginosa have therefore developed high-efficiency iron uptake systems that allow the bacteria to grow under iron-limited conditions, including when they grow as biofilms (Banin et al. 2005; Vasil and Ochsner 1999; Yang et al. 2007). These iron uptake systems may also recognise synthetic iron-binding compounds, thus resulting in some chelators being able to stimulate growth rather than inhibiting growth. For example, it was shown (Visca et al. 2013) that DFP inhibits planktonic growth 

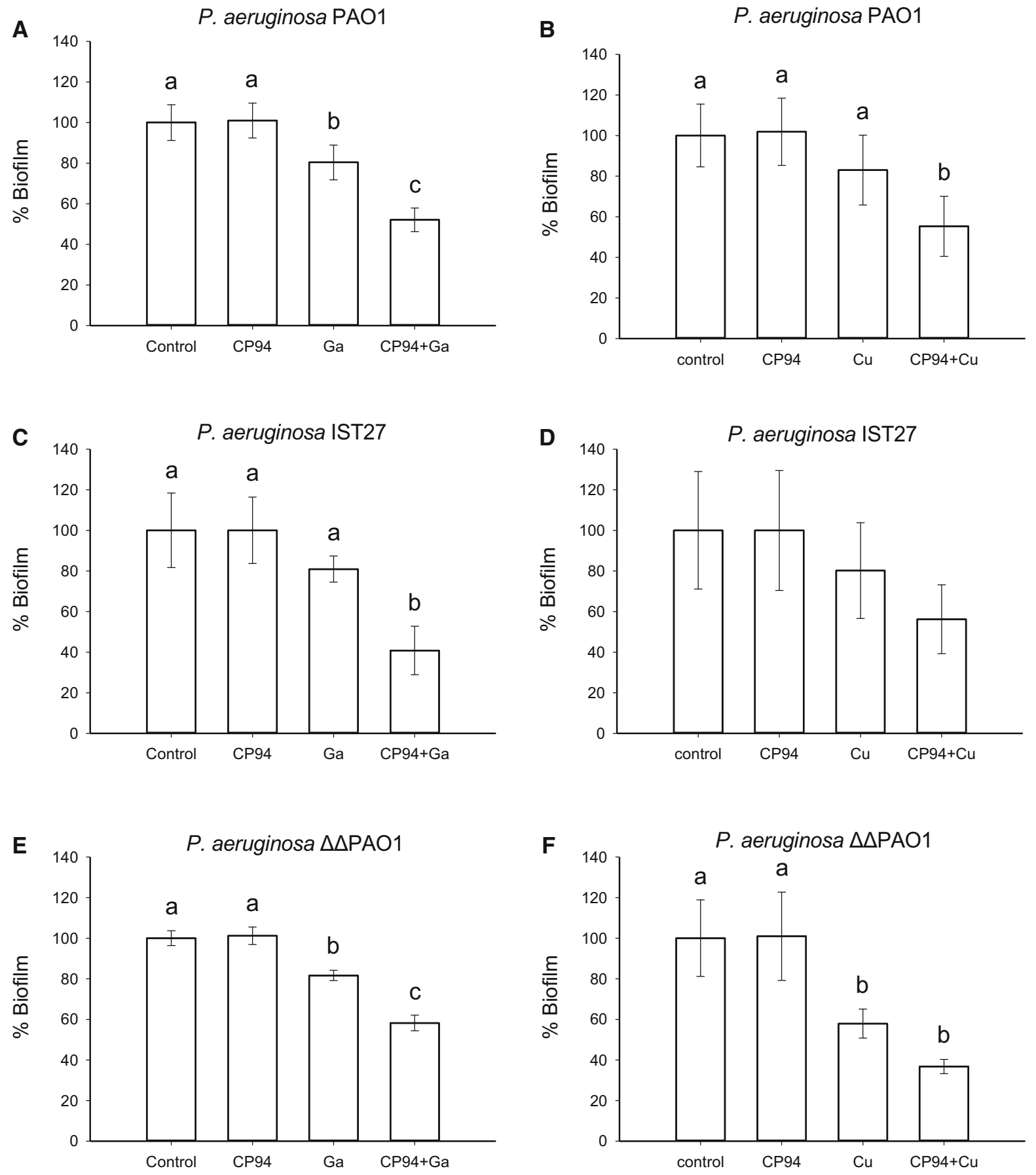

Fig. 5 Activity of CP94 with $\mathrm{Ga}^{3+}(\mathbf{a}, \mathbf{c}, \mathbf{e})$ and $\mathrm{Cu}^{2+}(\mathbf{b}, \mathbf{d}$, e) against biofilms of $P$. aeruginosa PAO1 (a, b), IST27 (c, d) and $\triangle \triangle \mathrm{PAO} 1(\mathbf{e}, \mathbf{f})$ in IMDM. Error bars indicate standard deviation of at least 3 independent experiments. Statistical analysis was done using a one-way ANOVA followed by a Tukey's posthoc test to compare pairwise the means of the

different treatments. Different letters indicate significant differences between treatments $(\mathrm{p}<0.05)$, whereas treatments indicated with the same letter are statistically not different from each other. If no letters are shown, none of the treatments showed statistically significant differences 


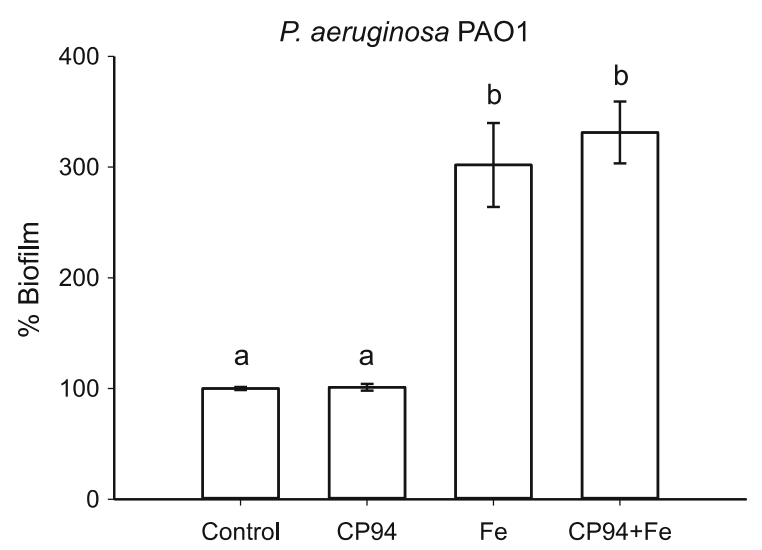

Fig. 6 Activity of CP94 with $\mathrm{Fe}^{3+}$ on biofilms of P. aeruginosa PAO1. Error bars indicate standard deviation of at least 3 independent experiments. Statistical analysis was done using a one-way ANOVA followed by a Tukey's posthoc test to compare pairwise the means of the different treatments. Different letters indicate significant differences between treatments $(\mathrm{p}<0.05)$, whereas treatments indicated with the same letter are statistically not different from each other

of $P$. aeruginosa at $0.92 \mathrm{mM}(=128 \mu \mathrm{g} / \mathrm{mL})$ but stimulates its growth rate at low concentrations, and the authors thus appropriately described such chelators as having a "dual personality".

Here we have found that the chelator CP94 can inhibit planktonic growth while promoting biofilm formation of $P$. aeruginosa. At high concentrations, it inhibits growth of planktonic cells, albeit that it is less toxic to $P$. aeruginosa than the closely related DFP. With respect to DFP, the MIC values determined in IMDM were similar to those determined in other studies (Richter et al. 2017; Thompson et al. 2012; Visca et al. 2013) even though these studies used different growth media. As mentioned above, the latter study also observed a stimulation of planktonic growth at low concentrations of DFP $(11-22 \mu \mathrm{g} / \mathrm{mL})$; we tested this at a similar range ( 8 and $16 \mu \mathrm{g} / \mathrm{mL})$ but did not observe such a stimulation (data not shown). That, however, could be a consequence of the different growth medium used.

We also found that the inhibitory concentrations of CP94 and DFP were significantly higher in rich (LB) or iron-supplemented IMDM medium, with MIC values for both CP94 and DFP being fourfold-to eightfold higher, showing that the iron concentration is the main determinant in the antimicrobial activity of these chelators. Thus in this case, the mechanism of action of these chelators is through limiting the amount of free iron. Both DFP and CP94 are bidentate chelators that form a defined 3:1 complex with ferric iron and with comparable affinities as judged by $\mathrm{pFe}^{3+}$ values, a reliable measure of iron affinity at physiologically relevant $\mathrm{pH}\left(\mathrm{pFe}^{3+}{ }_{\mathrm{DFP}}=20.6\right.$; $\mathrm{pFe}^{3+}$ CP94$=20.5$ ) (Ma et al. 2013). Some antimicrobial activity was, however, retained even though the chelators were fully saturated with $\mathrm{Fe}^{3+}$. This may indicate that, at high concentrations ( $>1024 \mu \mathrm{g} / \mathrm{mL}$ ), these chelators do have an iron-independent activity as also suggested previously (Visca et al. 2013).

The most interesting observation from our study is that CP94 stimulates formation of $P$. aeruginosa biofilms, in particular at high concentrations that are inhibitory to planktonic growth. In contrast, DFP is inhibitory to biofilm formation, and it is conceivable that this is because DFP limits the amount of iron that is available to cells. For CP94, one possible explanation for this could be that this compound leads to a general stress response, which in some cases has been shown to induce biofilm formation (Harms et al. 2016; Poole 2012). However, this does not seem to be very likely as CP94 behaved very differently to its simple homologue DFP, and this effect was much more pronounced in cells lacking the endogenous siderophores, pyoverdine and pyochelin. Moreover, there was no stimulation of biofilm formation of two other Gram-negative bacteria (E. coli and S. Typhimurium), indicating that under the conditions tested, the stimulatory effect of CP94 is specific to P. aeruginosa. Another mechanism of biofilm stimulation has been observed with sub-inhibitory concentrations of the antibiotic tobramycin, which can increase biofilm formation by about twofold to threefold in both $P$. aeruginosa and E. coli. This stimulation is a consequence of a change in levels of cyclic di-guanosine monophosphate via an aminoglycoside-specific response regulator (Hoffman et al. 2005). It seems very unlikely that $\mathrm{CP} 94$ would affect Arr, and this is therefore another mechanism of action that can be excluded.

We did not test whether the increase in biofilm formation of $P$. aeruginosa was due to an increased number of cells, an increase in the amount of extracellular polymeric substance (EPS) in biofilms, or both. However, we did analyse the effects of CP94 on the early stages of biofilm formation, by direct counting of the number of cells adherent to polystyrene after $6 \mathrm{~h}$ of incubation. This showed that in the 
presence of $\mathrm{CP} 94$ there were significantly more adherent cells, suggesting that at least in part the effects observed after $24 \mathrm{~h}$ are also due to an increased number of biofilm cells.

Based on our observations, we hypothesised that CP94, but not DFP, can act as a siderophore when $P$. aeruginosa cells are in a biofilm state. We did note that $4 \mu \mathrm{M}$ of $\mathrm{Fe}^{3+}$ alone can stimulate biofilm formation to a greater extent than CP94, and that addition of CP94 plus $\mathrm{Fe}^{3+}$ did not further of increase biofilm formation. However, at $4 \mu \mathrm{M}$ it seems likely that the transport of $\mathrm{Fe}^{3+}$ is not a rate limiting step which is why addition of CP94 to a growth medium that has sufficient amounts of $\mathrm{Fe}^{3+}$ does not lead to a additional stimulation of biofilm formation. Therefore, to support our hypothesis that CP94 can transport $\mathrm{Fe}^{3+}$, we investigated whether CP94 could promote the uptake of other metals. We analysed $\mathrm{Ga}^{3+}$ and $\mathrm{Cu}^{2+}$, both of which have antimicrobial activity and can also prevent biofilm formation in $P$. aeruginosa (Harrison et al. 2008; Kaneko et al. 2007). $\mathrm{Ga}^{3+}$ was of particular of interest, as it has the same charge and size as $\mathrm{Fe}^{3+}$ (Chitambar 2016; Harris and Sephton 1977; Harris and Pecoraro 1983), yet is not redox-active resulting in toxic effects. $\mathrm{Cu}^{2+}$ was included as the antimicrobial activity of the Cu-DFP complex against P.aeruginosa has been reported (Leite et al. 2019). In this study we confirmed that $\mathrm{Ga}^{3+}$ and $\mathrm{Cu}^{2+}$ are toxic to $P$. aeruginosa and, importantly, that CP94 stimulates the antimicrobial activity of these metals only when this bacterium is growing in a biofilm. At the concentrations used, both $\mathrm{Ga}^{3+}$ and $\mathrm{Cu}^{2+}$, on their own, reduced biofilms by $20-30 \%$, whereas this reduction was $\sim 40-60 \%$ in the presence of CP94. The concentration of the latter was well below the MIC value and on its own did not have an effect on growth, and we therefore conclude that the increased antimicrobial activity of $\mathrm{Ga}^{3+}$ and $\mathrm{Cu}^{2+}$ could be the effect of CP94-mediated transport of these metals. This contrasted with DFP, which did not stimulate the antibiofilm activity of $\mathrm{Ga}^{3+}$, so here only CP94 appears to show a "Trojan Horse" effect in which compounds may carry a toxic metal into cells (Golonka et al. 2019; Mjos et al. 2016). This effect has been demonstrated before in $P$. aeruginosa with a complex of $\mathrm{Ga}^{3+}$ and the chelator DFO, which was shown to kill planktonic cells and inhibit the formation of biofilms (Banin et al. 2008).
Several other $\mathrm{Ga}^{3+}$ complexes have also been tested on various microbes, indicating the potential for $\mathrm{Ga}^{3+}$ complexes as antimicrobial agents (Kelson et al. 2013). $\mathrm{Ga}^{3+}$ compounds have been used clinically, for instance in PET imaging (Price and Orvig 2014) and gallium nitrate is an FDA-approved therapeutic agent for malignancy-associated hypercalcemia (Bernstein 1998; Chitambar 2012). Gallium nitrate also inhibits $P$. aeruginosa, with MIC values that are in the same range as achievable in cancer therapy, albeit that the antimicrobial activity of gallium nitrate was strain dependent (Bonchi et al. 2015). Notably, the therapeutic concentration of gallium nitrate for hypercalcemia of malignancy is $10-15 \mu \mathrm{M}$ (Bernstein 1998). As shown here, $1 \mu \mathrm{M} \mathrm{Ga}^{3+}$ can inhibit biofilms by 40-60\% when complexed with CP94, and one might thus speculate that concentrations that effectively inhibit $P$. aeruginosa biofilms are therapeutically achievable. However, it is at this stage of course not known whether the toxicity of the Ga-CP94 complex is different from gallium nitrate, and whether GaCP94 is also active against $P$. aeruginosa biofilms in vivo. CP94 has been tested as an enhancer of 5-aminolaevulinic acid induced photodynamic therapy and photo diagnosis in vitro and in vivo (Blake et al. 2011; Campbell et al. 2008). It also has been tested for treatment of iron overload, and its toxicity appears to be species-dependent; in rat, at a dose of $100 \mathrm{mg} / \mathrm{kg}$, it effectively mobilised liver iron, but also showed some toxicity, while in guinea pig it lacked toxicity, but also lacked efficacy because of rapid inactivation (Porter et al. 1993). It is thus unclear whether CP94-Ga can be used as an anti-infective, and further tests are required for topical or systemic treatment of biofilm-related $P$. aeruginosa infections. With regards to copper, the concentration required to inhibit $P$. aeruginosa biofilms is considerably higher than for gallium, and it seems thus unlikely that effective doses of CP94-Cu are achievable considering the potential toxicity.

As shown here and in other studies, both copper and gallium have antimicrobial activity. For copper, its redox activity could be the reason for its antimicrobial properties, as it can act as a catalyst in Fenton and Haber-Weiss reactions, which result in the production of hydroxyl radicals that causes cellular damage (Grass et al. 2011). However, it has also been shown in $E$. coli there is no significant oxidative DNA damage in vitro (Macomber et al. 2007) and instead 
that there is non-redox dependent damage through the formation of $\mathrm{Cu}^{1+}$ ligands with sulfur clusters in dehydratases (Macomber and Imlay 2009). Bidentate chelators with a 3-hydroxypyridin-4-one structure such as DFP and CP94 form 2:1 complexes with $\mathrm{Cu}^{2+}$ (Leite et al. 2019), whereas in the case of $\mathrm{Ga}^{3+}$, DFP forms the expected 3:1 complex (Chaves et al. 2011) because not only it has the same charge as ferric ion, but also possesses a very similar ionic radius and shares the same preferred octahedral coordination geometry (Chitambar 2016; Harris and Sephton 1977; Harris and Pecoraro 1983). Therefore, $\mathrm{Ga}^{3+}$ is able to compete with $\mathrm{Fe}^{3+}$ to bind to iron-binding ligands in cells, such as heme and iron-sulfur cluster containing proteins. However, $\mathrm{Ga}^{3+}$ is, unlike $\mathrm{Fe}^{3+}$, not redox active and is not reduced to $\mathrm{Ga}^{2+}$ intracellularly, resulting in non-functional iron-dependent metabolic pathways which, in turn lead to bacterial cell death.

What remains still to be determined is how CP94 is taken up by $P$. aeruginosa. Generally, transport of iron in Gram-negative bacteria can follow a number of different routes. In P. aeruginosa, there are four such routes, being (a) uptake via siderophore complexes (in $P$. aeruginosa pyoverdine and pyochelin); (b) uptake via xenosiderophores, which are siderophores produced by other species; (c) uptake of heme from host heme proteins; and (d) uptake of ferrous iron (Cornelis and Dingemans 2013). The last route requires extracellular reduction of $\mathrm{Fe}^{3+}$ to $\mathrm{Fe}^{2+}$ and a dedicated FeoABC transporter (Cartron et al. 2006); this system is unlikely to be involved in what we observe here as, for instance, $\mathrm{Ga}^{3+}$ is not reduced under physiological conditions. The first three systems listed above all require specific TonB dependent receptors (TBDRs) in the outer membrane which are energised by a complex (TonB/ExbB/ExbD) in the cytoplasmic membrane, with transport across the cytoplasmic membrane being mediated by ABC transporters (Noinaj et al. 2010). For instance, ferric-pyoverdine is transported into the periplasm via the TBDRs FpvA and FpvB (Bodilis et al. 2009). In the periplasm, reduction of iron results in release from pyoverdine, and ferrous iron is then taken up through the ABC transporter FpvDE (Brillet et al. 2012). The route for ferripyochelin is somewhat different; the first step across the outer membrane is similar and involves the TonB-dependent receptor FptA (Ankenbauer and Quan 1994), but after this the entire ferripyochelin complex is taken up through the transporter FptX, and iron is released after reduction to
$\mathrm{Fe}^{2+}$ in the cytoplasm (Youard et al. 2011). Interestingly, there are $>30$ TonB-dependent receptors (Cornelis and Matthijs 2002), with some of these shown to be involved in the uptake of xenosiderophores (Cornelis and Dingemans 2013). Also, synthetic compounds may be taken up through such receptors and indeed, as mentioned before, DFP was shown to be taken up by planktonically growing $P$. aeruginosa cells at DFP concentrations that were below (20-160 $\mu \mathrm{M}$; equivalent to $2.75-22 \mu \mathrm{g} / \mathrm{mL}$ ) the MIC value (Visca et al. 2013). The receptor responsible for the uptake of DFP has not yet been identified but based on the results here it is likely to be a different receptor to the one responsible for the uptake of CP94, as the two compounds have opposite effects in our experiments, notwithstanding their very similar structures. We can also presume that this CP94 receptor is only expressed in cells that are growing as biofilms, as we did not observe the stimulatory effects on planktonic cells. Why the hypothetical CP94-receptor does transport DFP into cells is unclear at present. It is, however, interesting to note that CP94 is more lipophilic than DFP: the $\log$ D values for CP94 and its $\mathrm{Fe}^{3+}$ complex are 0.23 and -0.62 , whereas those for DFP and its $\mathrm{Fe}^{3+}$ complex are -0.77 and -2.60 , respectively (Rai et al. 1998). So it could be that the hypothetical receptor has different affinity for the two compounds, but it is also conceivable that the difference in lipophilicity influences the diffusion of the two compounds through the biofilm matrix.

Although speculative, a number of potential transport routes can be considered for CP94. One of these is, for several reasons, the pyochelin transport route. Firstly, a proteome analysis showed that FptA, the receptor for pyochelin, is strongly overproduced in biofilms in a minimal medium containing $10 \mathrm{mM}$ $\mathrm{Ca}^{2+}$, whereas there was no detectable production of FptA in either planktonic or biofilm cells in the absence of $\mathrm{Ca}^{2+}$ (Patrauchan et al. 2007). IMDM does contain $2 \mathrm{mM} \mathrm{CaCl}_{2}$, so it is conceivable that FptA is also overproduced in IMDM. It should however be noted that the medium used in that study also contains iron $(0.36 \mu \mathrm{M})$, whereas IMDM does not have iron in its formulation, and it is unclear what effect this or other nutrients have on the levels of FptA in biofilms as compared to planktonic cultures. Secondly, the results from that proteomics study are corroborated by a search of the GEO database (Barrett et al. 2013), which showed that in LB medium, fptA was shown to 
be strongly upregulated ( $>$ sevenfold) in biofilms when compared to either 4-h or 24-h planktonically grown cells (GEO accession GSE30021, accessed May 2020; (Costaglioli et al. 2012)). Thirdly, a study showed that pyochelin was able to stimulate the uptake of $\mathrm{Ga}^{3+}$ in P. aeruginosa, via FptA and FptX, whereas this was not observed for other pyoverdine or chelators that make use of other transport routes (Frangipani et al. 2014). It should be noted that the structures of CP94 and pyochelin are quite different, and it is thus unclear whether FptA would be able to recognise CP94. However, another TBDR that should be considered is PiuA, which was shown to recognise and stimulate transport of hydroxypyridone-conjugated beta-lactams such as BAL30072 and MC-1 in $P$. aeruginosa PAO1 (Brown et al. 2013; Moynié et al. 2017). It is therefore conceivable that PiuA is capable of facilitating the transport of other structural analogues containing the hydroxypyridone moiety, which includes CP94. Interestingly, the aforementioned transcriptome study (Costaglioli et al. 2012) showed that, in addition to FptA, the only other TBDR that was overproduced in biofilms was PiuA, albeit that the increase was only 1.5 fold to twofold. However, we do again need to point out the differences in growth conditions used, and it is not yet known whether PiuA is overproduced in biofilms grown in IMDM. Nevertheless, CP94-metal complexes could potentially utilise a number of transport routes, with potential candidates those involving the TBDRs FptA and PiuA. In the future we aim to provide more direct evidence for the transport route used, by for instance investigating the effect of $\mathrm{CP} 94$ on biofilm formation of mutants of $f p t A, p i u A$ or other genes encoding potential transporters.

Considering the activity of CP94-Ga and CP94-Cu on biofilms, it is also attractive to speculate on the clinical use of this complex as an antimicrobial agent since, as stated above, therapeutic concentrations of CP94-Ga ${ }^{3+}$ might be achievable. However, the applicability of CP94 complexes might also be somewhat limited as it is specific to biofilms and bacterial species that contain a CP94 uptake route. Our current research aims to explore the clinical applicability of CP94 further. Also of interest is to investigate whether CP94 could be used in combination with antibiotics, as several other chelator-antibiotic combinations have shown to have antimicrobial synergy (Chan et al. 2020; Lambert et al. 2004; van Asbeck et al. 1983b).

\section{Conclusion}

In conclusion, the chelator CP94, but not the closely related DFP, acts as a siderophore for $P$. aeruginosa when the cells are in a biofilm state. This shows, as previously proposed (Visca et al. 2013), that chelators can have either inhibitory or stimulatory activity depending on various factors. In this case, the siderophore-like behaviour of CP94 is specific to $P$. aeruginosa as it does not appear to be taken up by other Gram-negative bacteria, and it is specific to cells in the biofilm state. Future studies in our laboratory are aimed at determining the transport route of CP94 as well as investigating the potential of CP94 as an antiinfective-either on its own or in combination with antibiotics.

Acknowledgements We would like to thank Drs Emanuela Frangipani and Paolo Visca from the Roma Tre University for kindly providing $\mathrm{P}$. aeruginosa $\triangle \mathrm{PAO} 1$.

Funding This work was not funded by any external agency.

\section{Compliance with ethical standards}

Conflict of interest The authors declare no conflicts of interest.

Open Access This article is licensed under a Creative Commons Attribution 4.0 International License, which permits use, sharing, adaptation, distribution and reproduction in any medium or format, as long as you give appropriate credit to the original author(s) and the source, provide a link to the Creative Commons licence, and indicate if changes were made. The images or other third party material in this article are included in the article's Creative Commons licence, unless indicated otherwise in a credit line to the material. If material is not included in the article's Creative Commons licence and your intended use is not permitted by statutory regulation or exceeds the permitted use, you will need to obtain permission directly from the copyright holder. To view a copy of this licence, visit http://creativecommons.org/licenses/by/4.0/.

\section{References}

Abdul-Tehrani H, Hudson AJ, Chang YS, Timms AR, Hawkins C, Williams JM, Harrison PM, Guest JR, Andrews SC (1999) Ferritin mutants of Escherichia coli are iron deficient and growth impaired, and fur mutants are iron deficient. J Bacteriol 181:1415-1428

Andrews JM (2001) Determination of minimum inhibitory concentrations. J Antimicrob Chemother 48(Suppl 1):5-16 
Ankenbauer RG, Quan HN (1994) FptA, the Fe(III)-pyochelin receptor of Pseudomonas aeruginosa: a phenolate siderophore receptor homologous to hydroxamate siderophore receptors. J Bacteriol 176:307-319

Banin E, Lozinski A, Brady KM, Berenshtein E, Butterfield PW, Moshe M, Chevion M, Greenberg EP (2008) The potential of desferrioxamine-gallium as an anti-Pseudomonas therapeutic agent. Proc Natl Acad Sci USA 105:16761-16766

Banin E, Vasil ML, Greenberg EP (2005) Iron and Pseudomonas aeruginosa biofilm formation. Proc Natl Acad Sci USA 102:11076-11081

Barrett T, Wilhite SE, Ledoux P, Evangelista C, Kim IF, Tomashevsky M, Marshall KA, Phillippy KH, Sherman PM, Holko M, Yefanov A, Lee H, Zhang N, Robertson CL, Serova N, Davis S, Soboleva A (2013) NCBI GEO: archive for functional genomics data sets-update. Nucleic Acids Res 41:D991-995

Beeton ML, Aldrich-Wright JR, Bolhuis A (2014) The antimicrobial and antibiofilm activities of copper(II) complexes. J Inorg Biochem 140:167-172

Begg SL (2019) The role of metal ions in the virulence and viability of bacterial pathogens. Biochem Soc Trans 47:77-87

Bernstein LR (1998) Mechanisms of therapeutic activity for gallium. Pharmacol Rev 50:665-682

Blake E, Allen J, Curnow A (2011) An in vitro comparison of the effects of the iron-chelating agents, CP94 and dexrazoxane, on protoporphyrin IX accumulation for photodynamic therapy and/or fluorescence guided resection. Photochem Photobiol 87:1419-1426

Bodilis J, Ghysels B, Osayande J, Matthijs S, Pirnay JP, Denayer S, De Vos D, Cornelis P (2009) Distribution and evolution of ferripyoverdine receptors in Pseudomonas aeruginosa. Environ Microbiol 11:2123-2135

Bonchi C, Frangipani E, Imperi F, Visca P (2015) Pyoverdine and proteases affect the response of Pseudomonas aeruginosa to gallium in human serum. Antimicrob Agents Chemother 59:5641-5646

Brillet K, Ruffenach F, Adams H, Journet L, Gasser V, Hoegy F, Guillon L, Hannauer M, Page A, Schalk IJ (2012) An ABC transporter with two periplasmic binding proteins involved in iron acquisition in Pseudomonas aeruginosa. ACS Chem Biol 7:2036-2045

Brown MF, Mitton-Fry MJ, Arcari JT, Barham R, Casavant J, Gerstenberger BS, Han S, Hardink JR, Harris TM, Hoang T, Huband MD, Lall MS, Lemmon MM, Li C, Lin J, McCurdy SP, McElroy E, McPherson C, Marr ES, Mueller JP, Mullins L, Nikitenko AA, Noe MC, Penzien J, Plummer MS, Schuff BP, Shanmugasundaram V, Starr JT, Sun J, Tomaras A, Young JA, Zaniewski RP (2013) Pyridoneconjugated monobactam antibiotics with gram-negative activity. J Med Chem 56:5541-5552

Cabantchik ZI (2014) Labile iron in cells and body fluids: physiology, pathology, and pharmacology. Front Pharmacol 5:45

Campbell SM, Morton CA, Alyahya R, Horton S, Pye A, Curnow A (2008) Clinical investigation of the novel ironchelating agent, CP94, to enhance topical photodynamic therapy of nodular basal cell carcinoma. Br J Dermatol 159:387-393
Cartron ML, Maddocks S, Gillingham P, Craven CJ, Andrews SC (2006) Feo-transport of ferrous iron into bacteria. Biometals 19:143-157

Chan DCK, Guo I, Burrows LL (2020) Forging new antibiotic combinations under iron-limiting conditions. Antimicrob Agents Chemother 64:e01909-e1919

Chaves S, Mendonça AC, Marques SM, Prata MI, Santos AC, Martins AF, Geraldes CF, Santos MA (2011) A gallium complex with a new tripodal tris-hydroxypyridinone for potential nuclear diagnostic imaging: solution and in vivo studies of 67Ga-labeled species. J Inorg Biochem 105:31-38

Chitambar CR (2012) Gallium-containing anticancer compounds. Future. Med Chem 4:1257-1272

Chitambar CR (2016) Gallium and its competing roles with iron in biological systems. Biochim Biophys Acta 1863:2044-2053

Cornelis P, Dingemans J (2013) Pseudomonas aeruginosa adapts its iron uptake strategies in function of the type of infections. Front Cell Infect Microbiol 3:75

Cornelis P, Matthijs S (2002) Diversity of siderophore-mediated iron uptake systems in fluorescent pseudomonads: not only pyoverdines. Environ Microbiol 4:787-798

Costaglioli P, Barthe C, Claverol S, Brözel VS, Perrot M, Crouzet M, Bonneu M, Garbay B, Vilain S (2012) Evidence for the involvement of the anthranilate degradation pathway in Pseudomonas aeruginosa biofilm formation. Microbiologyopen 1:326-339

Cunrath O, Geoffroy VA, Schalk IJ (2016) Metallome of Pseudomonas aeruginosa: a role for siderophores. Environ Microbiol 18:3258-3267

Daher R, Manceau H, Karim Z (2017) Iron metabolism and the role of the iron-regulating hormone hepcidin in health and disease. Presse Med 46:e272-e278

Diggle SP, Matthijs S, Wright VJ, Fletcher MP, Chhabra SR, Lamont IL, Kong X, Hider RC, Cornelis P, Camara M, Williams P (2007) The Pseudomonas aeruginosa 4-quinolone signal molecules HHQ and PQS play multifunctional roles in quorum sensing and iron entrapment. Chem Biol 14:87-96

Frangipani E, Bonchi C, Minandri F, Imperi F, Visca P (2014) Pyochelin potentiates the inhibitory activity of gallium on Pseudomonas aeruginosa. Antimicrob Agents Chemother 58:5572-5575

Golonka R, Yeoh BS, Vijay-Kumar M (2019) The iron tug-ofwar between bacterial siderophores and innate immunity. J Innate Immun 11:249-262

Grass G, Rensing C, Solioz M (2011) Metallic copper as an antimicrobial surface. Appl Environ Microbiol 77:1541-1547

Grenier F, Matteau D, Baby V, Rodrigue S (2014) Complete genome sequence of Escherichia coli BW25113. Genome Announc 2:e01038-e1114

Harms A, Maisonneuve E, Gerdes K (2016) Mechanisms of bacterial persistence during stress and antibiotic exposure. Science 354:aaf4268

Harris AW, Sephton RG (1977) Transferrin promotion of 67Ga and $59 \mathrm{Fe}$ uptake by cultured mouse myeloma cells. Cancer Res 37:3634-3638

Harris WR, Pecoraro VL (1983) Thermodynamic binding constants for gallium transferrin. Biochemistry 22:292-299 
Harrison JJ, Turner RJ, Joo DA, Stan MA, Chan CS, Allan ND, Vrionis HA, Olson ME, Ceri H (2008) Copper and quaternary ammonium cations exert synergistic bactericidal and antibiofilm activity against Pseudomonas aeruginosa. Antimicrob Agents Chemother 52:2870-2881

Hider RC, Kong X (2010) Chemistry and biology of siderophores. Nat Prod Rep 27:637-657

Hoffman LR, D'Argenio DA, MacCoss MJ, Zhang Z, Jones RA, Miller SI (2005) Aminoglycoside antibiotics induce bacterial biofilm formation. Nature 436:1171-1175

Holloway BW (1955) Genetic recombination in Pseudomonas aeruginosa. J Gen Microbiol 13:572-581

Kaneko Y, Thoendel M, Olakanmi O, Britigan BE, Singh PK (2007) The transition metal gallium disrupts Pseudomonas aeruginosa iron metabolism and has antimicrobial and antibiofilm activity. J Clin Invest 117:877-888

Kelson AB, Carnevali M, Truong-Le V (2013) Gallium-based anti-infectives: targeting microbial iron-uptake mechanisms. Curr Opin Pharmacol 13:707-716

Kim CM, Shin SH (2009) Effect of iron-chelator deferiprone on the in vitro growth of staphylococci. J Korean Med Sci 24:289-295

Kortman GA, Mulder ML, Richters TJ, Shanmugam NK, Trebicka E, Boekhorst J, Timmerman HM, Roelofs R, Wiegerinck ET, Laarakkers CM, Swinkels DW, Bolhuis A, Cherayil BJ, Tjalsma H (2015) Low dietary iron intake restrains the intestinal inflammatory response and pathology of enteric infection by food-borne bacterial pathogens. Eur J Immunol 45:2553-2567

Lai YW, Campbell LT, Wilkins MR, Pang CN, Chen S, Carter DA (2016) Synergy and antagonism between iron chelators and antifungal drugs in Cryptococcus. Int $\mathrm{J}$ Antimicrob Agents 48:388-394

Lambert RJ, Hanlon GW, Denyer SP (2004) The synergistic effect of EDTA/antimicrobial combinations on Pseudomonas aeruginosa. J Appl Microbiol 96:244-253

Leite A, Bessa L, Silva A, Gameiro P, de Castro B, Rangel M (2019) Antibacterial activity of naphthyl derived bis-(3hydroxy-4-pyridinonate) copper(II) complexes against multidrug-resistant bacteria. J Inorg Biochem 197:110704

Leitão JH, Alvim T, Sá-Correia I (1996) Ribotyping of Pseudomonas aeruginosa isolates from patients and water springs and genome fingerprinting of variants concerning mucoidy. FEMS Immunol Med Microbiol 13:287-292

Lowy FD, Pollack S, Fadl-Allah N, Steigbigel NH (1984) Susceptibilities of bacterial and fungal urinary tract isolates to desferrioxamine. Antimicrob Agents Chemother 25:375-376

Ma Y, Xie Y, Hider RC (2013) A novel fluorescence method for determination of $\mathrm{pFe} 3+$. Analyst 138:96-99

Macomber L, Imlay JA (2009) The iron-sulfur clusters of dehydratases are primary intracellular targets of copper toxicity. Proc Natl Acad Sci USA 106:8344-8349

Macomber L, Rensing C, Imlay JA (2007) Intracellular copper does not catalyze the formation of oxidative DNA damage in Escherichia coli. J Bacteriol 189:1616-1626

Mjos KD, Cawthray JF, Polishchuk E, Abrams MJ, Orvig C (2016) Gallium(iii) and iron(iii) complexes of quinolone antimicrobials. Dalton Trans 45:13146-13160
Moon JH, Herr Y, Kim SW, Lee JY (2011) In vitro activity of deferoxamine against Porphyromonas gingivalis. FEMS Microbiol Lett 323:61-67

Moynié L, Luscher A, Rolo D, Pletzer D, Tortajada A, Weingart H, Braun Y, Page MG, Naismith JH, Köhler T (2017) Structure and function of the PiuA and PirA siderophoredrug receptors from Pseudomonas aeruginosa and Acinetobacter baumannii. Antimicrob Agents Chemother 61:e02531-e2616

Mulcahy LR, Isabella VM, Lewis K (2014) Pseudomonas aeruginosa biofilms in disease. Microb Ecol 68:1-12

Neilands JB (1995) Siderophores: structure and function of microbial iron transport compounds. J Biol Chem 270:26723-26726

Noinaj N, Guillier M, Barnard TJ, Buchanan SK (2010) TonBdependent transporters: regulation, structure, and function. Annu Rev Microbiol 64:43-60

Patrauchan MA, Sarkisova SA, Franklin MJ (2007) Strainspecific proteome responses of Pseudomonas aeruginosa to biofilm-associated growth and to calcium. Microbiology 153:3838-3851

Poole K (2012) Stress responses as determinants of antimicrobial resistance in Gram-negative bacteria. Trends Microbiol 20:227-234

Porter JB, Abeysinghe RD, Hoyes KP, Barra C, Huehns ER, Brooks PN, Blackwell MP, Araneta M, Brittenham G, Singh S (1993) Contrasting interspecies efficacy and toxicology of 1,2-diethyl-3-hydroxypyridin-4-one, CP94, relates to differing metabolism of the iron chelating site. $\mathrm{Br}$ J Haematol 85:159-168

Price EW, Orvig C (2014) Matching chelators to radiometals for radiopharmaceuticals. Chem Soc Rev 43:260-290

Rai BL, Dekhordi LS, Khodr H, Jin Y, Liu Z, Hider RC (1998) Synthesis, physicochemical properties, and evaluation of N-substituted-2-alkyl-3-hydroxy-4(1H)-pyridinones. J Med Chem 41:3347-3359

Richter K, Thomas N, Claeys J, McGuane J, Prestidge CA, Coenye T, Wormald PJ, Vreugde S (2017) A topical hydrogel with deferiprone and gallium-protoporphyrin targets bacterial iron metabolism and has antibiofilm activity. Antimicrob Agents Chemother 61:e00481-e517

Singh S, Epemolu RO, Dobbin PS, Tilbrook GS, Ellis BL, Damani LA, Hider RC (1992) Urinary metabolic profiles in human and rat of 1,2-dimethyl- and 1,2-diethyl-substituted 3-hydroxypyridin-4-ones. Drug Metab Dispos 20:256-261

Thompson MG, Corey BW, Si Y, Craft DW, Zurawski DV (2012) Antibacterial activities of iron chelators against common nosocomial pathogens. Antimicrob Agents Chemother 56:5419-5421

Toledo-Arana A, Valle J, Solano C, Arrizubieta MJ, Cucarella C, Lamata M, Amorena B, Leiva J, Penades JR, Lasa I (2001) The enterococcal surface protein, Esp, is involved in Enterococcus faecalis biofilm formation. Appl Environ Microbiol 67:4538-4545

van Asbeck BS, Marcelis JH, Marx JJ, Struyvenberg A, van Kats $\mathrm{JH}$, Verhoef J (1983a) Inhibition of bacterial multiplication by the iron chelator deferoxamine: potentiating effect of ascorbic acid. Eur J Clin Microbiol 2:426-431

van Asbeck BS, Marcelis JH, van Kats JH, Jaarsma EY, Verhoef J (1983b) Synergy between the iron chelator deferoxamine and the antimicrobial agents gentamicin, chloramphenicol, 
cefalothin, cefotiam and cefsulodin. Eur J Clin Microbiol 2:432-438

Vasil ML, Ochsner UA (1999) The response of Pseudomonas aeruginosa to iron: genetics, biochemistry and virulence. Mol Microbiol 34:399-413

Visca P, Bonchi C, Minandri F, Frangipani E, Imperi F (2013) The dual personality of iron chelators: growth inhibitors or promoters? Antimicrob Agents Chemother 57:2432-2433

Yang L, Barken KB, Skindersoe ME, Christensen AB, Givskov M, Tolker-Nielsen T (2007) Effects of iron on DNA release and biofilm development by Pseudomonas aeruginosa. Microbiology 153:1318-1328

Youard ZA, Wenner N, Reimmann C (2011) Iron acquisition with the natural siderophore enantiomers pyochelin and enantio-pyochelin in Pseudomonas species. Biometals 24:513-522

Zarember KA, Cruz AR, Huang CY, Gallin JI (2009) Antifungal activities of natural and synthetic iron chelators alone and in combination with azole and polyene antibiotics against Aspergillus fumigatus. Antimicrob Agents Chemother 53:2654-2656

Publisher's Note Springer Nature remains neutral with regard to jurisdictional claims in published maps and institutional affiliations. 